\title{
Camshaft Failure Simulation with Static Structural Approach
}

\author{
Riduwan Prasetya, Andoko*, Suprayitno \\ Mechanical Engineering Department, Universitas Negeri Malang, Jl. Semarang 5, 65145, \\ Indonesia \\ *Corresponding author:andoko.ft@um.ac.id
}

\begin{abstract}
A failure happens within the camshaft of the minibus when the vehicle is in utilize. The camshaft was a fracture within the bearing between the primary cylinder exhaust valve and the second cylinder suction. This simulation aims to find the causes of camshaft failure utilizing the finite element method with a static structural approach, including simulations of deformation, strain, stress, fatigue life (stress-life and strainlife), and cracks. The method used in this paper is the finite element method with a static structural approach by ANSYS software. The camshaft material is a gray cast iron designed using Solidworks. Pre-processing includes meshing with a size of $3 \mathrm{~mm}$. The value of loading force $(1348.28 \mathrm{~N})$ and torque $(113400 \mathrm{Nmm})$ are fixed, and the boundary conditions are varied. Processing includes the process of computation and postprocessing into a part that displays the results. The simulation results show that for all the deformation and strain values that are in the elasticity area of the material, the maximum and minimum stress which is below the strength of the material, the location of the maximum values of deformation, strain, and stress is not at the fault location. The simulation of fatigue life both in stress-life and strain-life results in infinite cycles, which is above $10^{6}$ cycles, while the simulation of cracks results in a decrease in the cycle. Based on the simulation results with the above parameters to the camshaft, it was found that a failure was caused by a defect characterized by reduced fatigue life at the same loading conditions.
\end{abstract}

Copyright (C) 2021. Journal of Mechanical Engineering Science and Technology.

Keywords: ANSYS, Camshaft, Failure Analysis, Simulation, Static Structural

\section{Introduction}

A combustion engine is a power producer whose complex structure plays an important role today [1]. Composed of essential components that support each other in generating power, one of the critical components is the camshaft. The camshaft is a shaft with a cam that functions to open and close the suction and exhaust valves so that the combustion process can occur [2]. When a failure occurs, the engine cannot run properly and causes problems that impact losses [3]. For example, the owner of a Toyota minibus who suffered a damaged camshaft in a broken car was used. A break occurred between the exhaust valve of the first cylinder and the inlet cylinder of the second. Repair is the right step to resolve these problems, but preventive action is also much more critical so that similar failures do not occur. Taking preventative measures would have to know the causes of an object that fails, one of them with failure analysis [4].

Static structural failure analysis is an approach to analyze the causes of the failure of a structure [5]. There are various methods used to analyze the failures using experiments and simulations. Experiments include macroscopic examination, microscopic examination, material characterization (metallographic analysis, mechanical testing, chemical analysis), 
and residual stress measurement. Simulation using the finite element method consists of stress analysis and fracture mechanics. A finite element method is a numerical approach to engineering problems that have been developed since 1950 [6]. This method has more advantages compared to experimental testing [7]. The finite element method gives a lot of variation in the test to provide a broader picture to the researchers. This simulation aims to find the causes of camshaft failure using the finite element method with a static structural approach, including simulations of deformation, strain, stress, fatigue life (stress-life and strain-life), and cracks.

The previous simulation by Patil et al. regarding the camshaft failure analysis is the one that analyzes the camshaft using the modal and camshaft fatigue on the pump [8]. Wang et al. predicts camshaft fatigue fracture under bending and torsional loads and provides cracks [9]. Suhas et al., in 2011, conducted a contact fatigue analysis of the camshaft [10].

\section{Material and Methods}

\section{A. Material}

The camshaft material was determined by a chemical composition test using the Hilger E-9 OA701 Spectrometer (Table 1) and compared with the standard to obtain a gray cast iron material [11]. The mechanical properties of gray cast iron are shown in Table 2.

Table 1. Chemical composition of gray cast iron [11]

\begin{tabular}{cc}
\hline Chemical Composition & Wt.\% \\
\hline $\mathrm{C}$ & $3.10-3.60$ \\
$\mathrm{Si}$ & $1.95-2.40$ \\
$\mathrm{Mn}$ & $0.60-0.90$ \\
$\mathrm{P}$ & Max. 0.10 \\
$\mathrm{~S}$ & Max. 0.15 \\
$\mathrm{Cr}$ & $0.85-1.25$ \\
$\mathrm{Mo}$ & $0.40-0.60$ \\
$\mathrm{Ni}$ & $0.20-0.45$ \\
\hline
\end{tabular}

Table 2. Mechanical properties of gray cast iron [11]

\begin{tabular}{lr}
\hline Tensile strength & $220 \mathrm{MPa}$ \\
Compression strength & $669 \mathrm{MPa}$ \\
Torsional shear strength & $220 \mathrm{MPa}$ \\
Maximum deflection & $4.3 \mathrm{~mm}$ \\
\hline
\end{tabular}

\section{B. Methods}

The method used was the finite element method or simulated with the help of ANSYS. Stages on the finite element method with static structural approaches include pre-processing, processing, and post-processing. 


\section{Pre-Processing}

Pre-Processing was the initial step in the simulation. The step was first designing the camshaft according to actual conditions using Solidworks and export using .sat format (Figure 1). Then imported into the ANSYS software and added gray cast iron as camshaft's material. After that, generate mesh with size of $3 \mathrm{~mm}$ for accurate results. Meshing produced 339,270 nodes and 226,400 elements for simulating deformation, strain, stress, stress-life, and strain-life. For crack simulation, it used meshing with default size and tetrahedron meshing for more stable results.

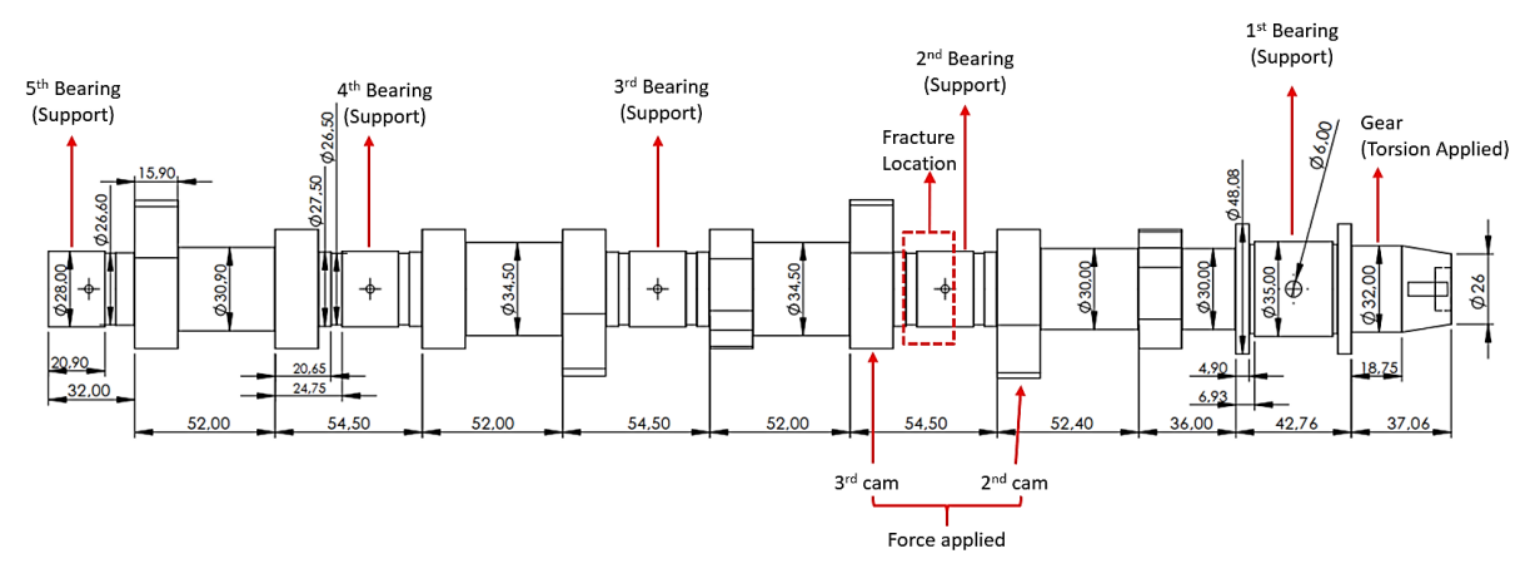

Fig. 1. Camshaft's design

Deformation, strain, and stress simulations were carried out with a fixed value loading force $(1348.3 \mathrm{~N})$ at the ends of cam 2 and 3 and torque $(113400 \mathrm{Nmm})$. The support in these conditions is fixed, and cylindrical support is varied and shown in Table 1 Appendix. This variation aimed to find the value and location of the highest deformation, strain, and stress. The location of load (force and torsion) and support is shown in Figure 1.

Fatigue life simulation was done by applying load and boundary conditions which give the highest stress to the camshaft (obtained from previous simulations). In the fatigue life approach that uses stress-life and strain-life, defects were ignored, while defects were applied to the crack simulation approach. The location of the defect in the form of a crack is shown in Figure 2 with 6 points.

\section{Processing}

Processing was a calculation step performed by a computer. The calculation was based on the load and boundary conditions that have been entered in the previous process.

\section{Post-Processing}

After the calculation process was completed, the post-processing would display the results of the calculations. In deformation, strain, and stress simulation, the captured data was the minimum and maximum value of each condition and their distribution indicated by the color bar on the camshaft (visually). In the life simulation (stress-life, strain-life, and cracks), the results taken were the fatigue life of the components. Data values (maximum, minimum, and life) were taken from tabular data generated by ANSYS. 


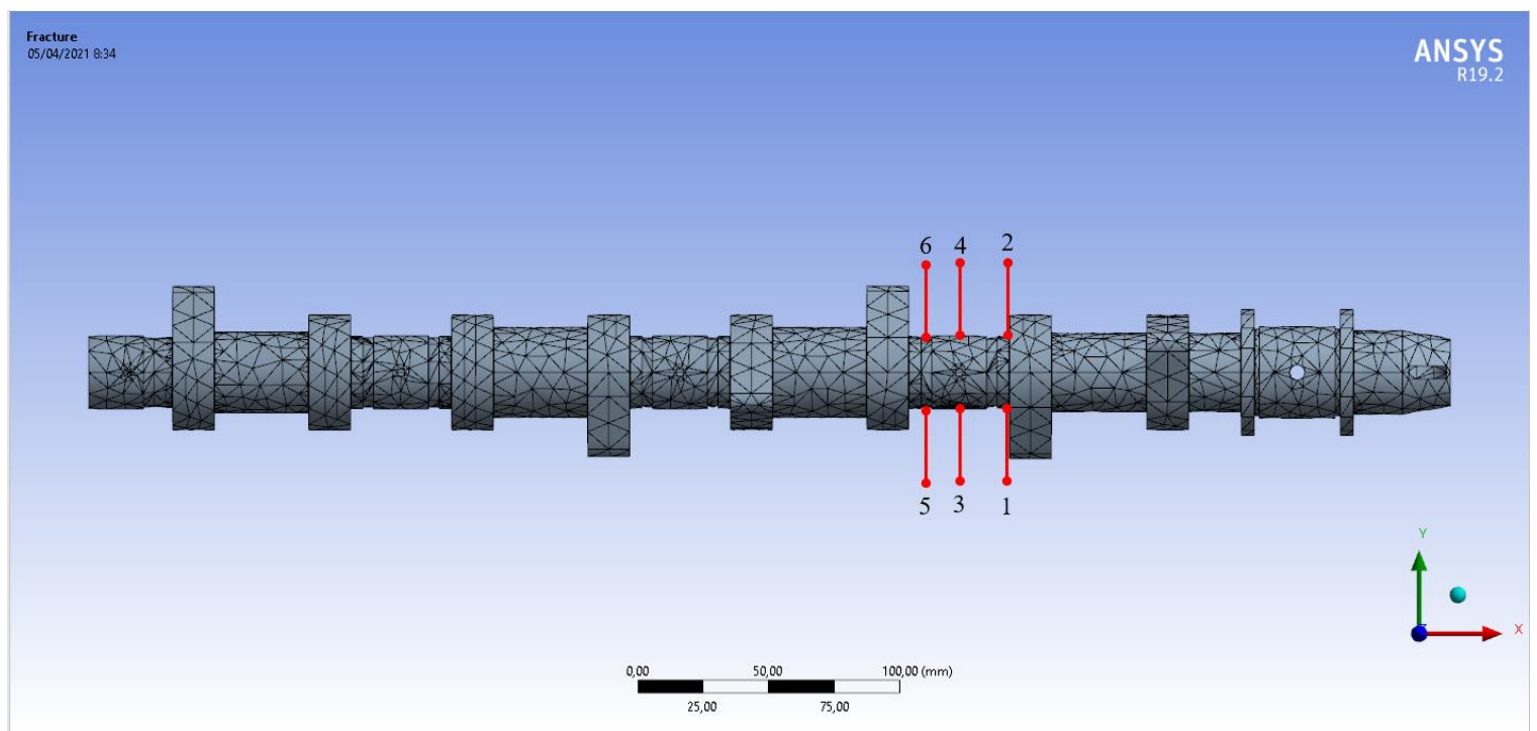

Fig. 2. Crack location

\section{Results and Discussions}

\section{A. Deformation}

The deformation simulation results for the maximum values of various conditions are shown in Figure 3. At conditions 1 to 42, the deformation values are below $0.02 \mathrm{~mm}$. This condition occurs when all bearings are held both by cylindrical support and a fixed support. The deformation value then increases at condition 43 and moves up and down in the range $0.02 \mathrm{~mm}$ to $0.10727 \mathrm{~mm}$ (except $46^{\text {th }}$ condition), which support in $43^{\text {rd }}$ to $51^{\text {st }}$ condition is fixed support on the second bearing. The force exerted in the y-axis direction results in lower deformation than the force in the yz-axis direction and the torque. The added torque makes the maximum deformation value increase to $0.005 \mathrm{~mm}$.

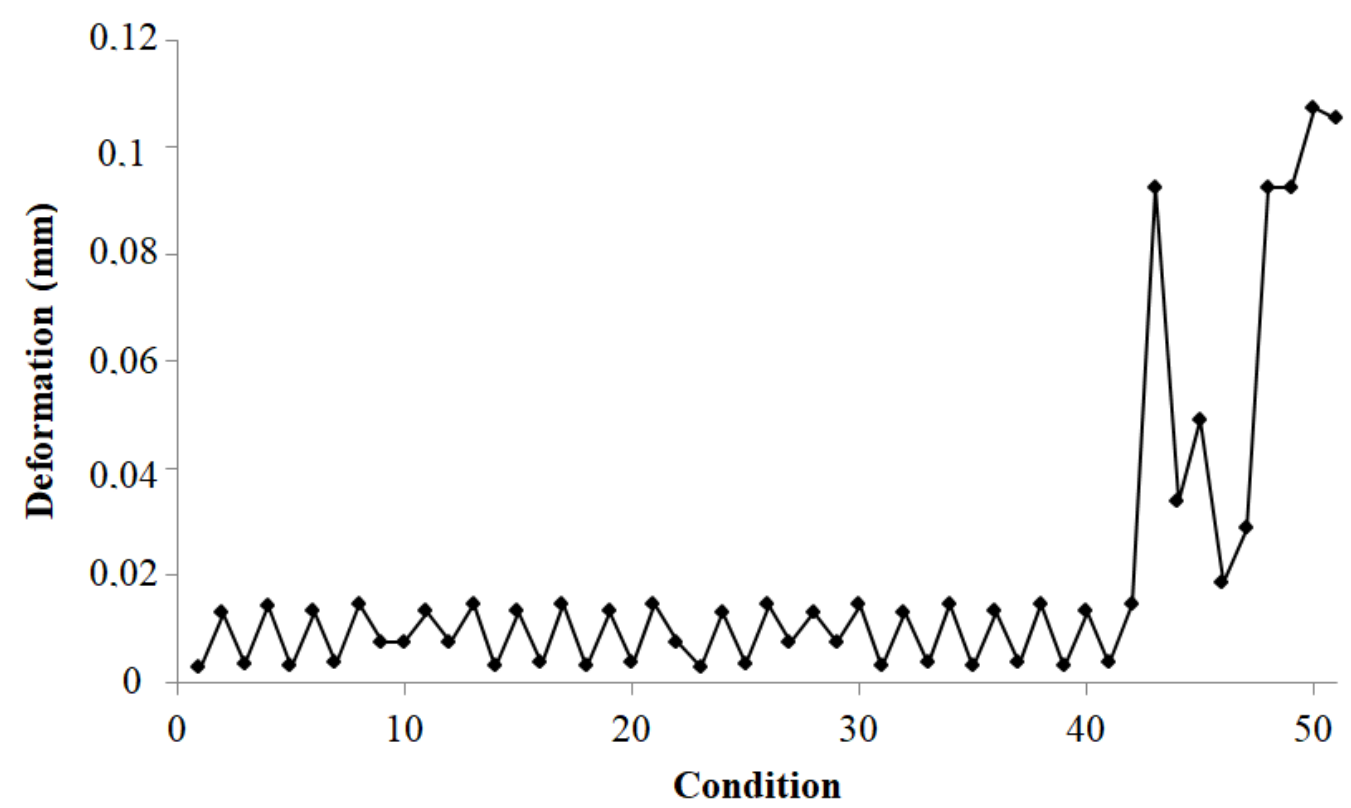

Fig. 3. Maximum deformation of various conditions 
The location of the maximum deformation under which all bearings held and applied is at the cam end where the force applied (Figure 4 (a)). When torque is used, the location of the maximum deformation shifts to an area close to the site of the given torque (Figure 4 (b)). However, this does not apply to torque loading with force in the yz direction. The maximum deformation is at the end of the cam. Different things are shown in the condition of 43 to 51 . When the load is given to $3^{\text {rd }}$ cam, the maximum deformation is located at the left end of the camshaft. At the same time, the force applied to the second cam and the load torque of maximum deformation is at the right end of the camshaft. The location of maximum deformation has never been in part a fracture camshaft.

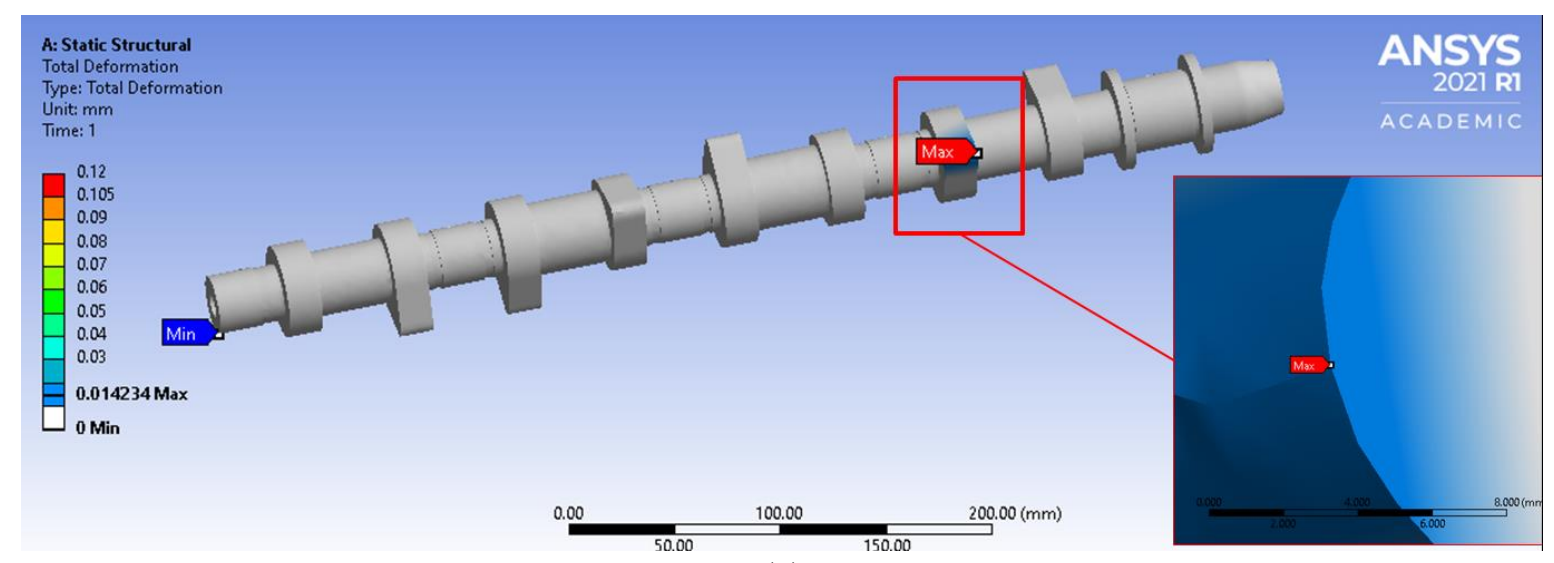

(a)

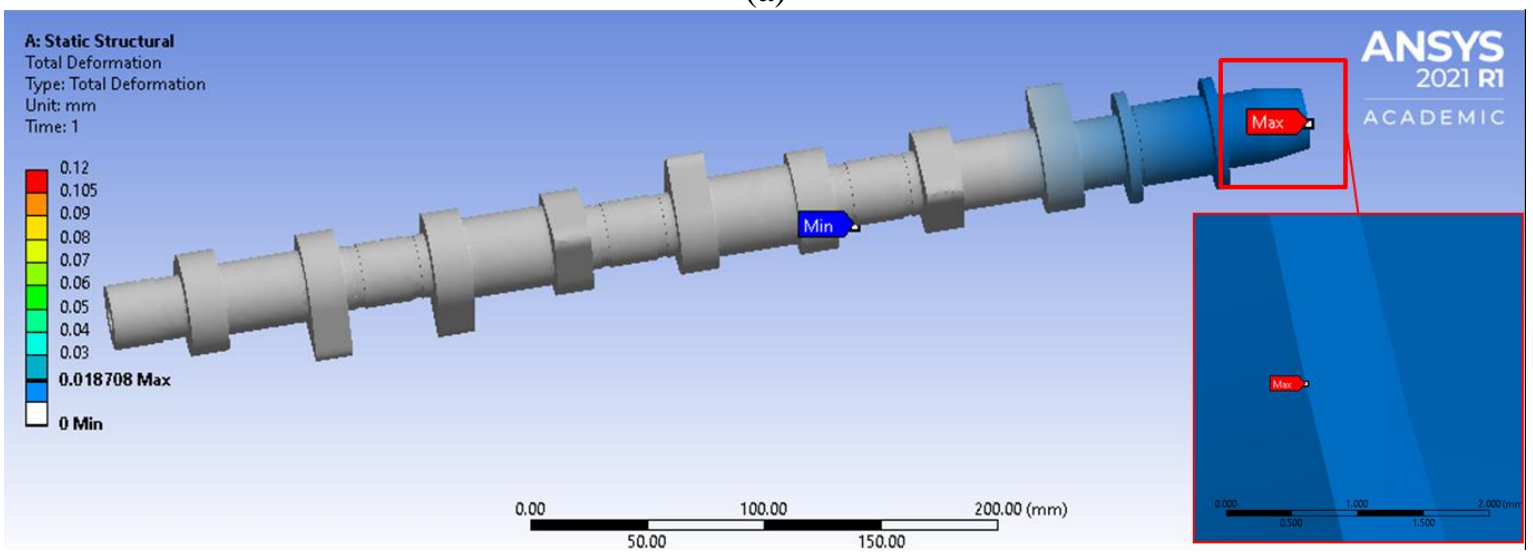

(b)

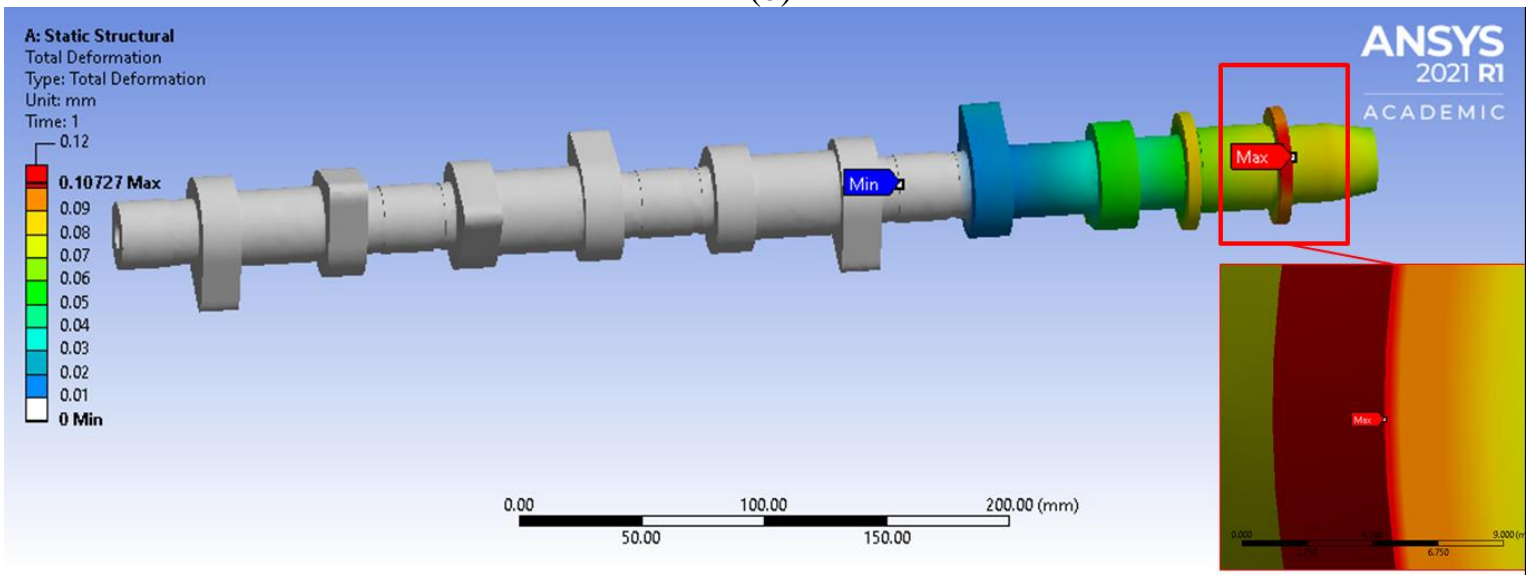

(c)

Fig. 4. Location of maximum deformation at (a) $4^{\text {th }}$ (b) $46^{\text {th }}$ (c) $50^{\text {th }}$ condition 
The maximum deformation value for various conditions is $0.10727 \mathrm{~mm}$, which occurs in $50^{\text {th }}$ condition (Figure $4(\mathrm{c})$ ). $50^{\text {th }}$ condition is the loading in the form of a force on $2^{\text {nd }}$ cam and torque and $2^{\text {nd }}$ bearing being held. Compared with the maximum deflection value of the material $(4.3 \mathrm{~mm})$, the resulting deformation is far below this value, therefore did not lead to plastic deformation. The change is unable to reverse and fails [11].

\section{B. Strain}

The maximum strain for each condition is shown in the graph in Figure 5. The value of the strain varies from $0.02 \%$ to $0.12 \%$. As with the deformation simulation results, when all the bearings are held, the result is lower than one bearing. The highest strain was $0.12406 \%$ which occurred at $50^{\text {th }}$ condition (the same as the maximum deformation) (Figure 6 (c)).

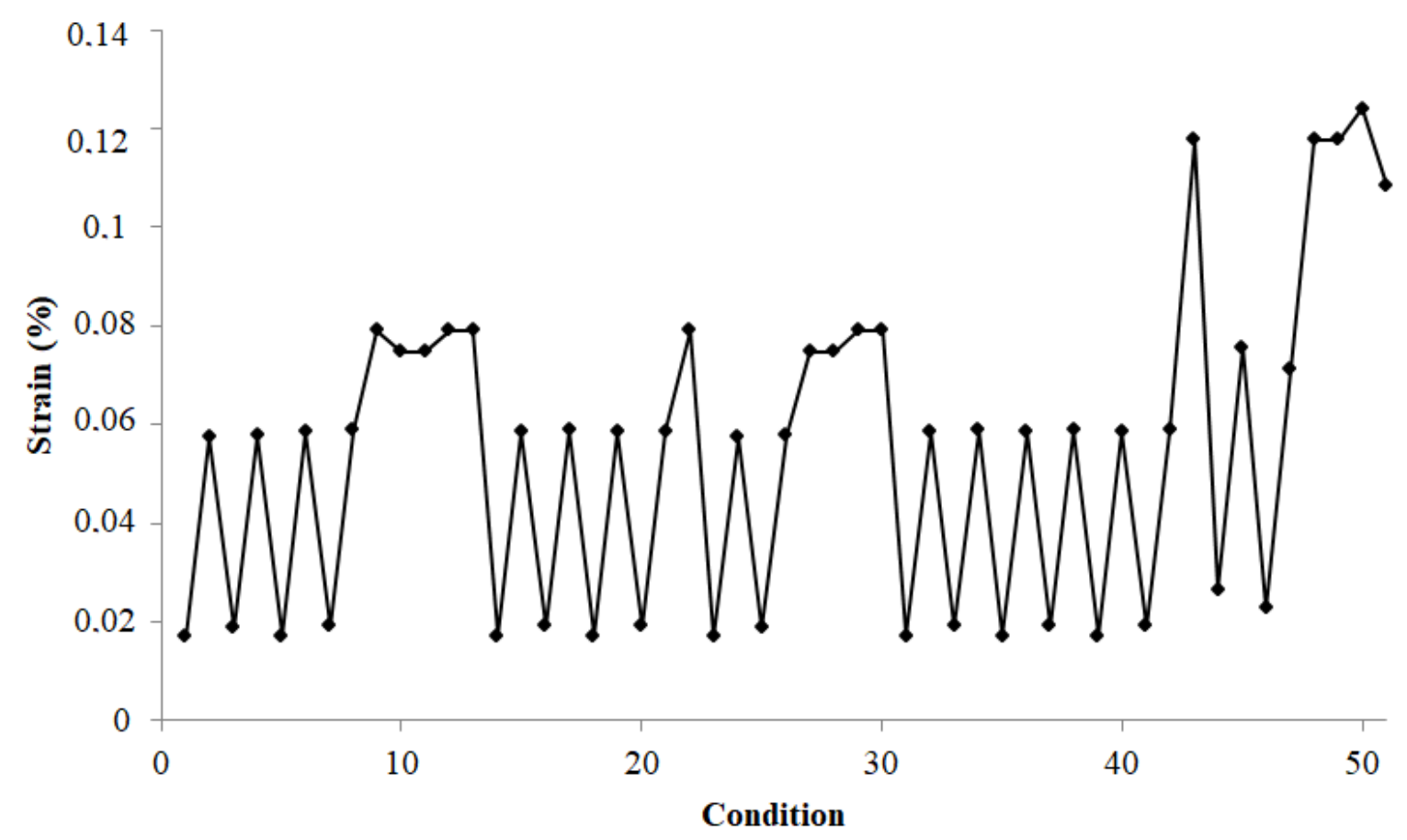

Fig. 5. Maximum strain in various conditions

The location of the maximum strain when only the force is applying with all the bearings held is on the side cam (Figure 6 (b)). Meanwhile, if the load is torsional, then the location of the maximum strain is located on the side of the camshaft's gear (Figure 6 (a)). Both occur in areas undergoing geometric changes. In the fault area, it has never experienced the highest strain.

Strain and deformation have a relationship in explaining the changes in shape in objects [12]. The various loading conditions given indicate that these conditions do not lead to failure. The strain simulation results confirm it. The resulting strain is below 1\%, which means that the camshaft is deforming elastically [13]. According to Hooke's law, further evidence shown in the graph of stress and strain in Figure 7 forms a linear line. In terms of the location where the maximum value is, both deformation and strain show that the maximum value never occurs in the fracture area. 


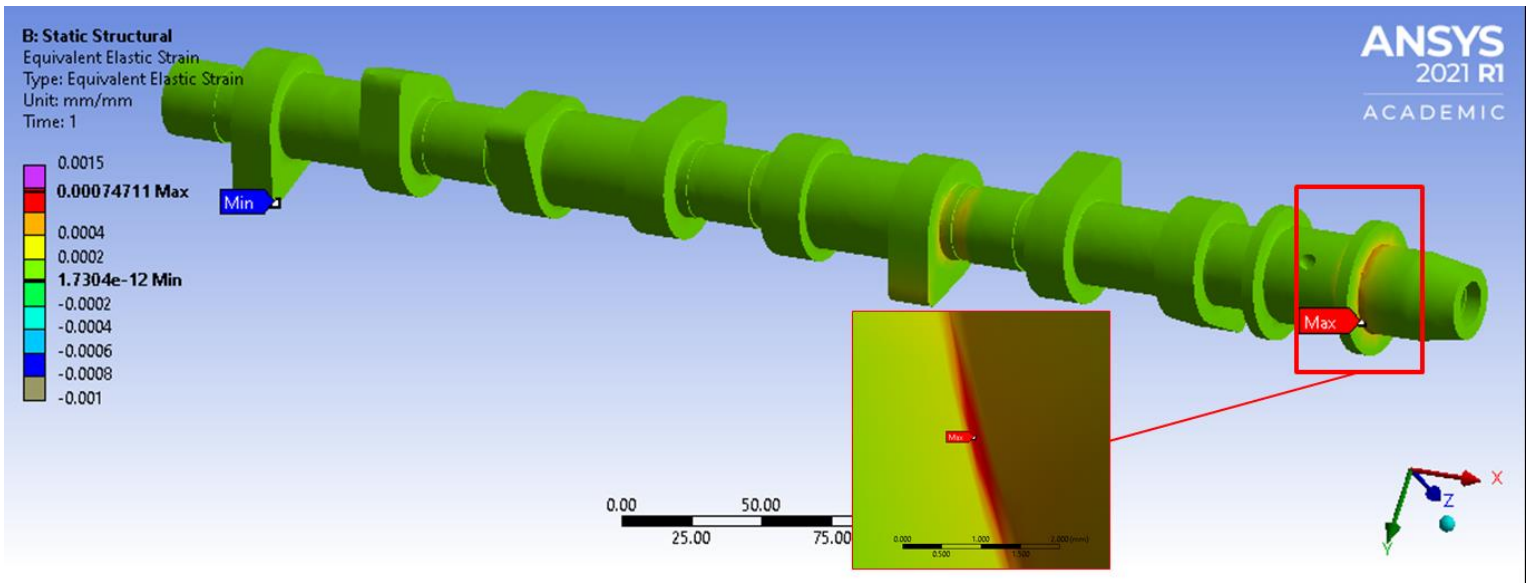

(a)

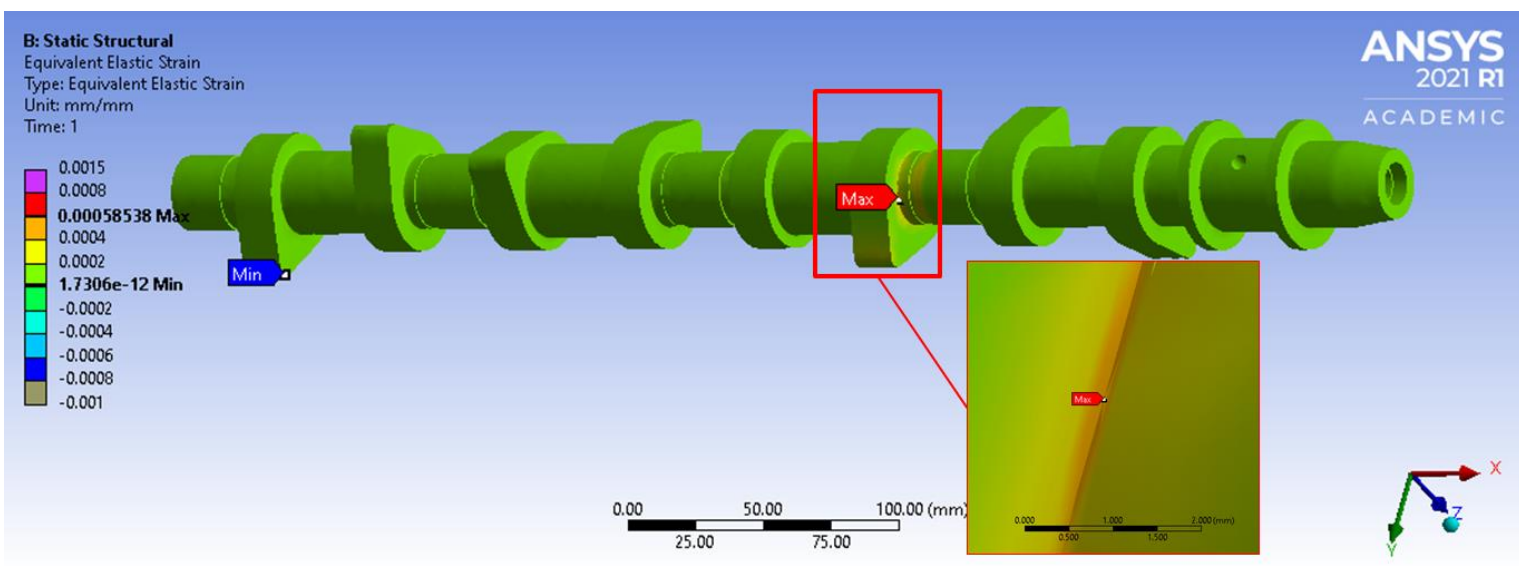

(b)

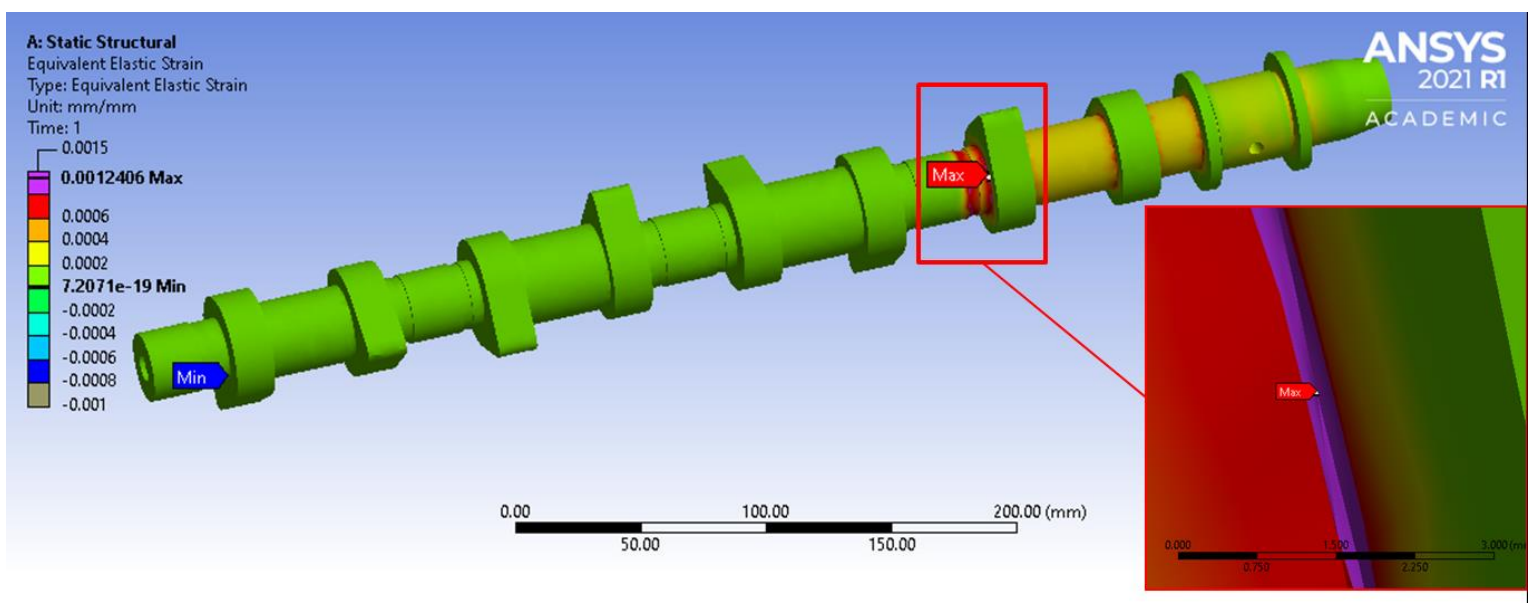

(c)

Fig. 6. Location of maximum strain at (a) $11^{\text {th }}$ (b) $19^{\text {th }}$ (c) $50^{\text {th }}$ condition 


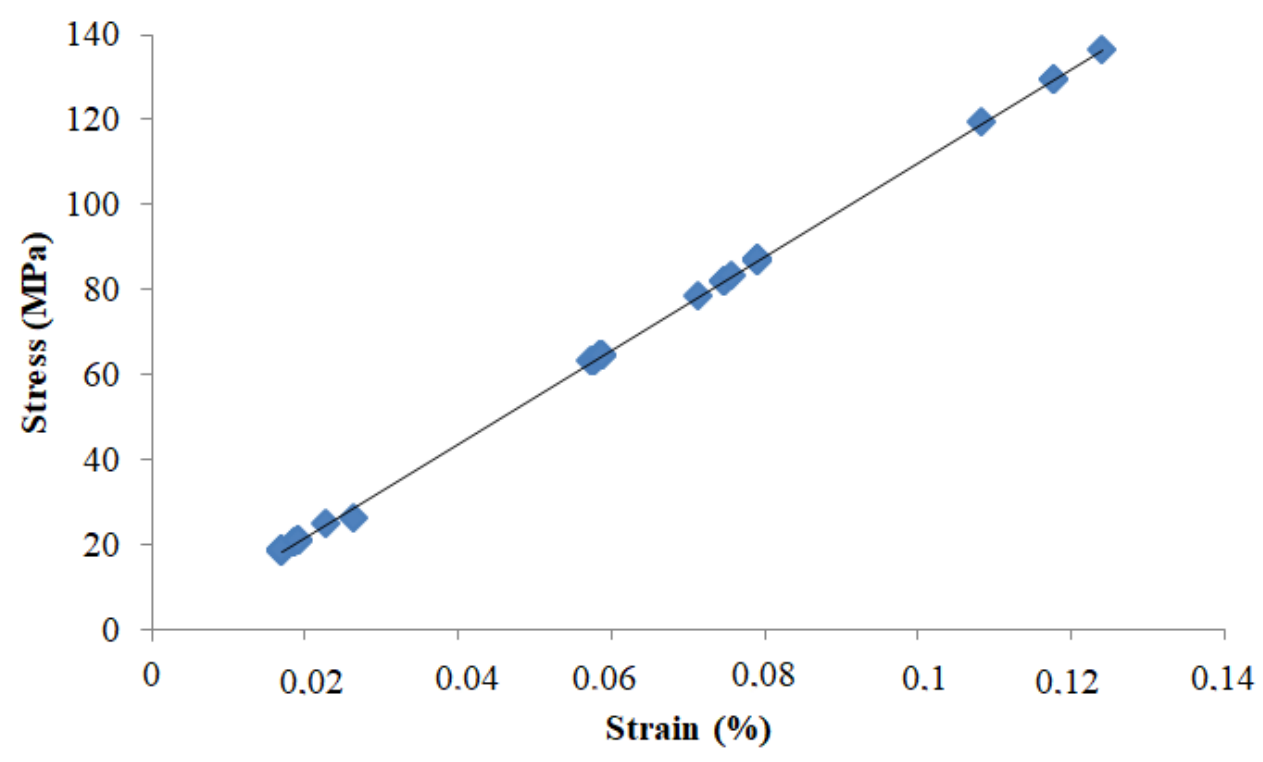

C. Stress

Fig. 7. Stress vs. Strain

Figure 8 shows the maximum and minimum stress results for various conditions. The stress approach used includes Von Misses, Maximum Principal Stress, and Minimum Principal Stress. Under conditions when all bearings are held, resulting in lower stress than one bearing held. Maximum stress on von misses, and principal stress is $136.4 \mathrm{MPa}$ and $79.814 \mathrm{MPa}$, respectively. Both occur at the $50^{\text {th }}$ condition. Meanwhile, minimum principal stress is $-84.392 \mathrm{MPa}$ that occur at the $51^{\text {st }}$ condition.

Based on Mohr's Modification theory, the failure approach for brittle materials can be done by comparing the maximum stress with the Ultimate Tensile Strength (UTS) and the minimum stress with the Ultimate Compressive Strength (UCS) [14]. The Von Misses Stress simulation yields a higher value than the Principal Stress, and when compared to the tensile strength of the material $(220 \mathrm{MPa})$, the value is below it. The same thing is also shown by the Minimum Principal Stress, which is far below the value of the compression material strength $(669 \mathrm{MPa})$. Both indicate that the stress applied to the camshaft does not result in failure.

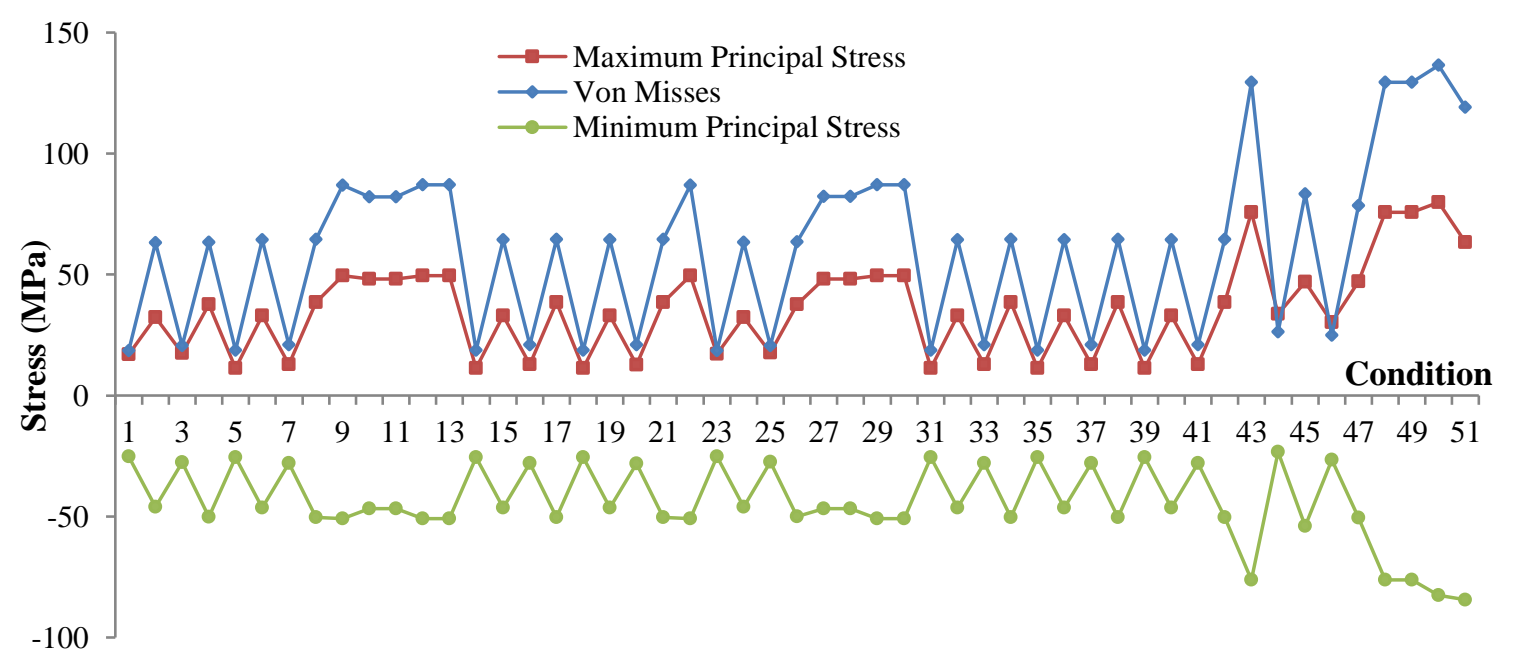

Fig. 8. Maximum and minimum stress in various conditions 
The location of the maximum stress (Von Misses and Maximum Principal) has the same position as the maximum strain. The location of the maximum von misses stress, and principal stress is shown in Figure 19 (a) and (b), while the minimum principal stress is in Figure 19 (c). Fracture areas tend to be subjected to lower or even lowest stresses when these conditions are applied. This show that the fault location has never experienced the highest stress as long as the load is applied.

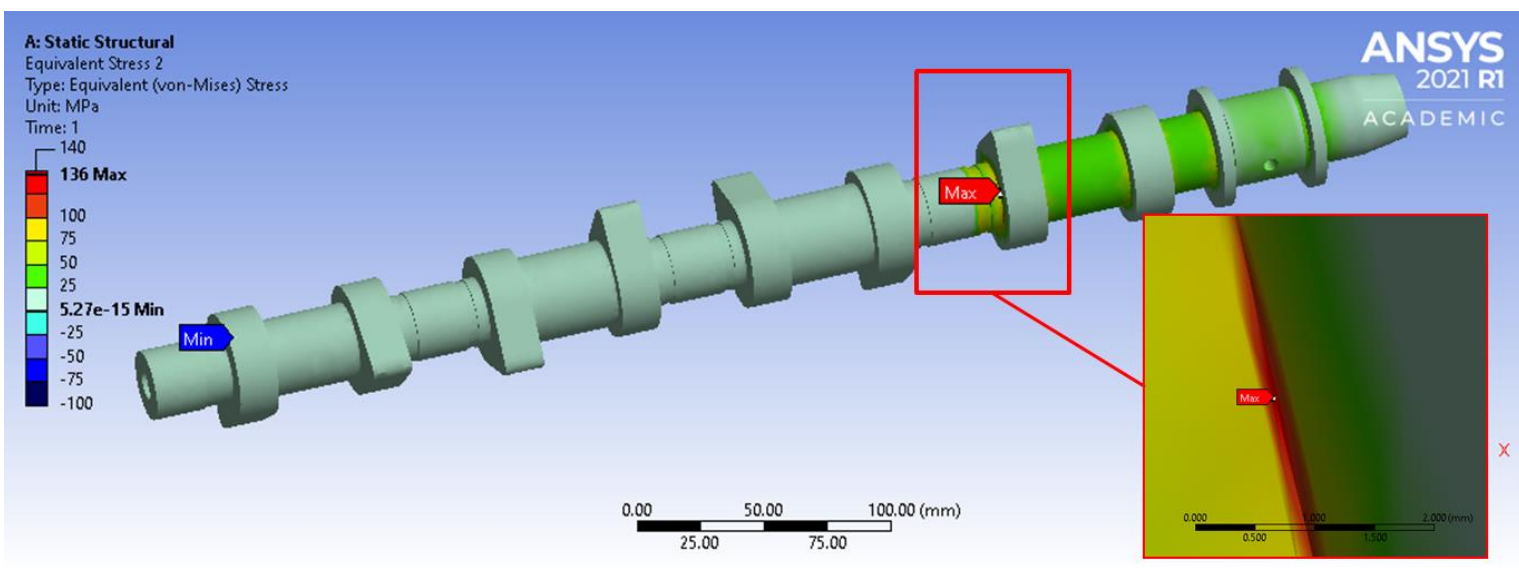

(a)

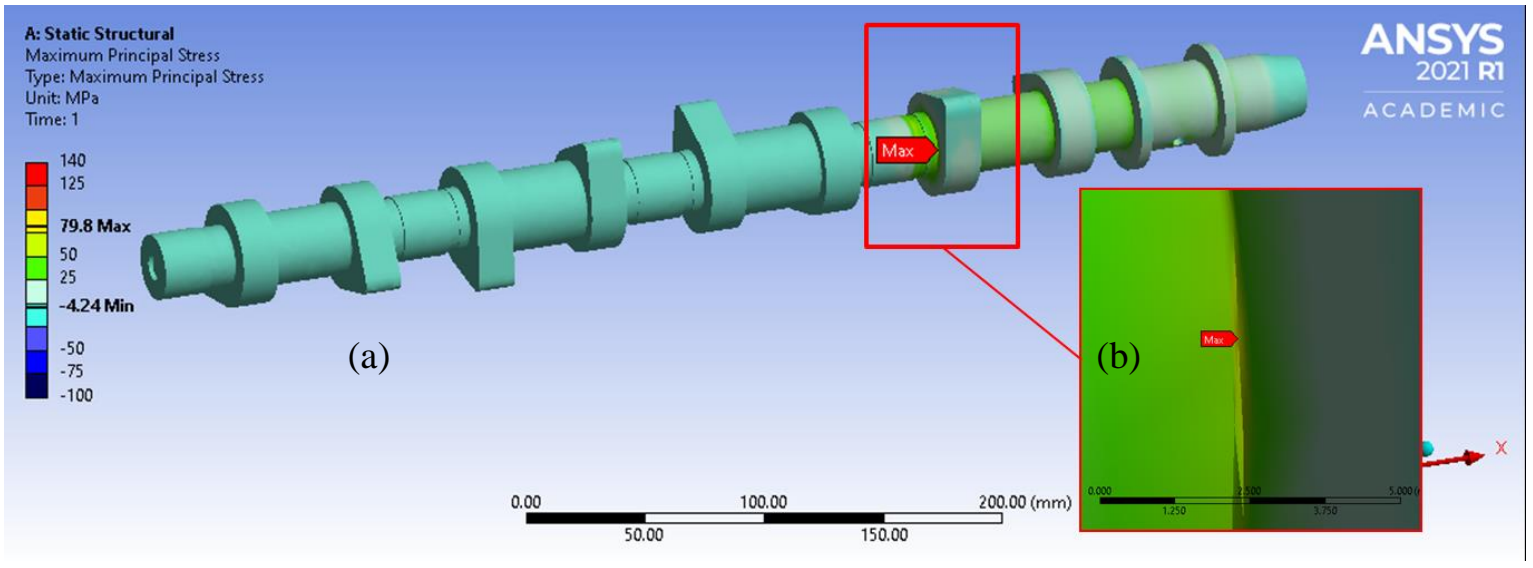

(b)

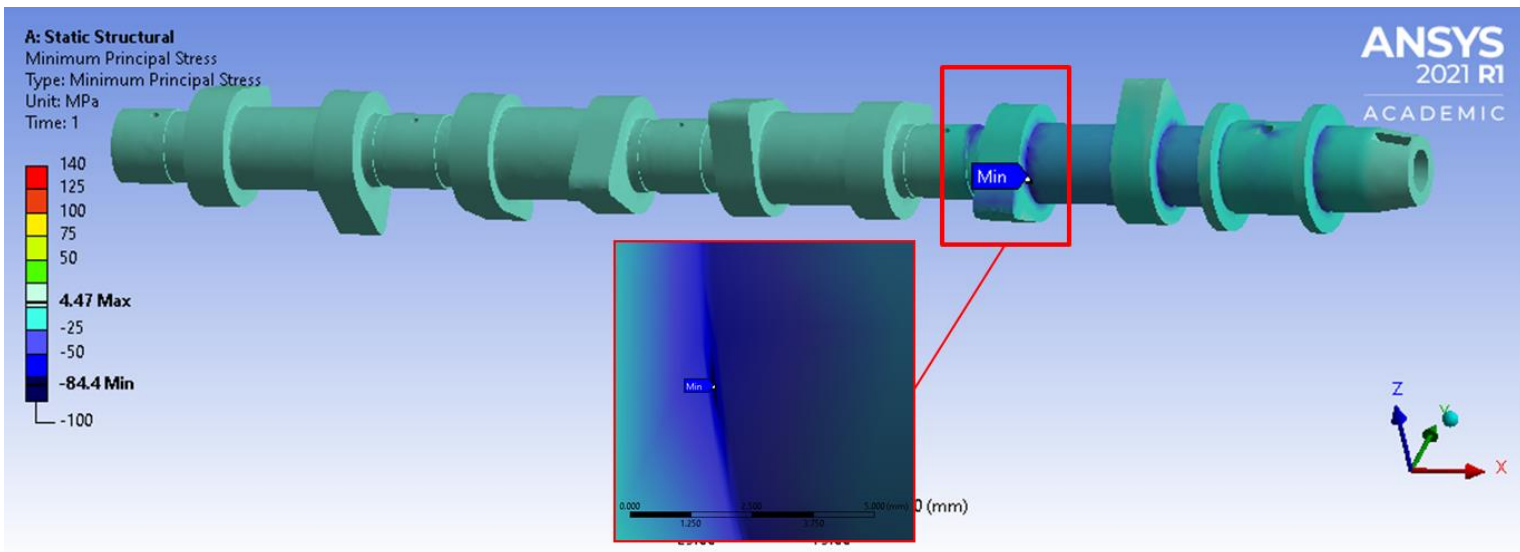

(c)

Fig. 9. Location of (a) maximum von misses stress at $50^{\text {th }}$ condition (b) maximum principal stress at $50^{\text {th }}$ condition (c) minimum principal stress at $51^{\text {st }}$ condition 
Deformation, strain, and stress simulation results are similar. The result is a load applied to various conditions in the region show elasticity and below the strength of the material. In terms of location, the highest value has never occurred in a fractured area. In relation to the failure, the load applied is not the cause of a fracture in the camshaft.

\section{Stress - Life dan Strain Life}

The stress life and strain life simulations results are shown in Table 3. Simulation of material fatigue life using stress-life and strain-life approaches is a fatigue approach in which the camshaft is considering no defects [15] [16]. The applied loading is the condition with the highest maximum stress and strain in the previous simulation. The results show that for stress-life, the fatigue life is $2 \times 10^{7}$ cycles. At the same time, the strain life approach is $10^{9}$ cycles. Based on the fatigue theory, when the number of cycles reaches $10^{6}$ without damage, it can be mentioned that the components can last indefinitely / infinite cycles [17]. This shows that the stress applied to the camshaft will not break the camshaft or within the endurance limit of the material.

Table 3. Stress-life and Strain-life result

\begin{tabular}{ll}
\hline Stress-life $(\sigma-N)$ & $2 \times 10^{7}$ cycles \\
Strain-life $(\varepsilon-N)$ & $1 \times 10^{9}$ cycles \\
\hline
\end{tabular}

\section{E. Crack}

Simulations with defects to determine the camshaft life are carried out by providing cracks with shape like in Figure 10 in part shown in Figure 2. Points 1 and 2 are the areas with the highest stress, and points 3 to 6 are the fracture locations.
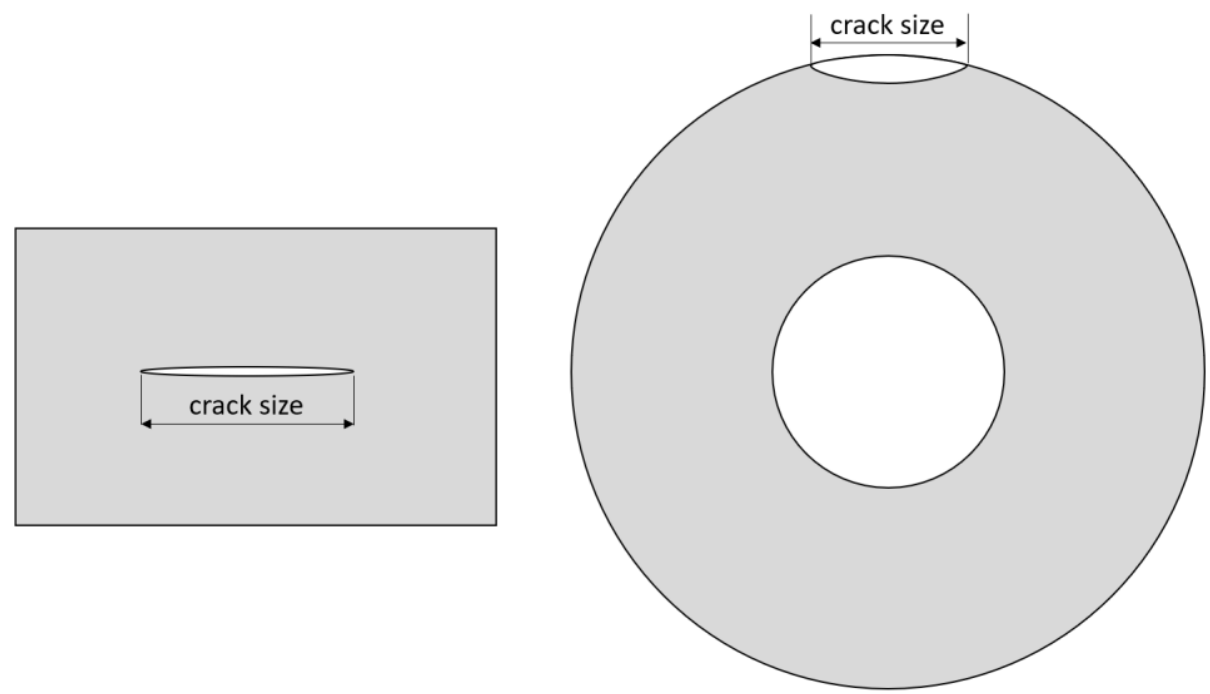

Fig. 10. Crack Shape

Figure 11 shows the crack simulation results. The size of the cracks varied from 0.05 $\mathrm{mm}$ to $0.5 \mathrm{~mm}$ at points 1 and 2. Cracks placed in position 1 gave a lower lifespan than cracks placed in position 2 (Figure 11 (a)). With a crack size of $0.5 \mathrm{~mm}$, position 2 requires 
88 cycles to break, while position 1 requires 594 cycles. The more minor cracks were 0.05 mm, 39775 cycles, and 302950 cycles at positions 1 and 2 for fracture.

Figure 11(b) shows the simulation results when the crack is placed at points 3 to 6 (fault area) with a crack size of $0.5 \mathrm{~mm}$ to $2 \mathrm{~mm}$. It is seen that the life of crack growth is greater than that of the cracks placed in positions 1 and 2 . Given a crack of $0.5 \mathrm{~mm}$, all four show an age of more than 1010 cycles.

When compared with the simulation without defect, it is seen that giving a defect shortens the life of the camshaft with the same load. Although the age values in the stresslife and strain-life simulations are smaller than the crack simulations at a specific defect size, this is influenced by the age limits included in the stress-life and strain-life tests. The crack simulation shows that when the component reaches its maximum value, it indicates that it is a failure. Thus, camshaft failure results from a defect characterized by reduced fatigue life under the same loading conditions, and experimental testing is needed to further review the defects that occur.

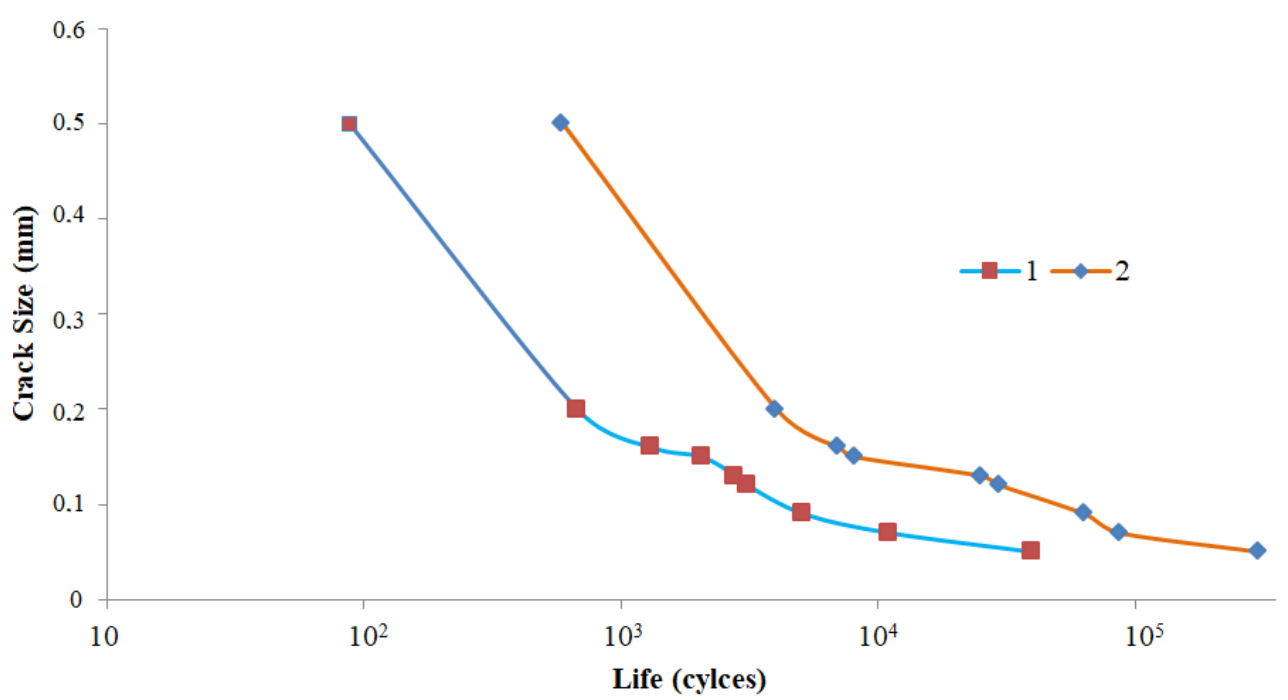

(a)

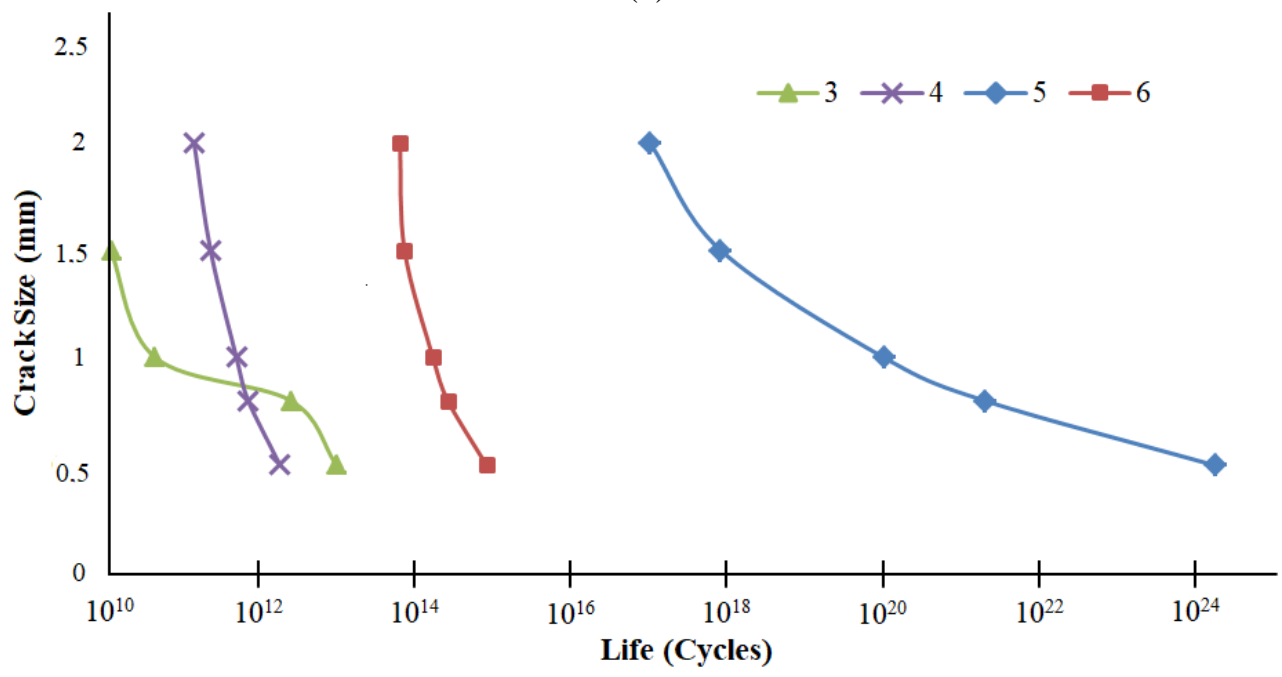

(b)

Fig. 11. Fatigue life with variation in crack size (a) Locations 1 and 2 (b) Locations 3-6 


\section{Conclusions}

Based on the simulated parameters (deformation, strain, stress, life, and cracks), camshaft fracture is not caused by the load applied but by defects. Deformation and strain simulations show that the resulting value is in the area of elasticity of the material. The stress-strain graph, which produces a linear line, also reinforces this result. The stress simulation shows that the highest location of stress does not occur in the fault area, and the value is below the strength of the material. In the crack simulation, it is seen that giving a defect shortens the life of the camshaft with the same load as the stress-life and strain-life simulations. This simulation indicates that the defect results in camshaft failure, characterized by reduced fatigue life under the same loading conditions.

\section{References}

[1] Lubis, D.Z., and Andoko, "Elastic Linear Analysis of Connecting Rods for Single Cylinder Four Stroke Petrol Engines Using Finite Element Method," J. Mech. Eng. Sci. Technol., vol. 3(1), pp. 42-50, 2019.

[2] Lin, D.-Y., Hou, B.-J., and Lan, C.-C., "A Balancing Cam Mechanism for Minimizing the Torque Fluctuation of Engine Camshafts," Mech. Mach. Theory, vol. 108, pp. 160-175, 2017.

[3] Andoko and Amin, W. R., "Investigation of Stress, Deformation, and Cracks in the Brakes of Car Using Finite Element Method," IOP Conf. Ser. Mater. Sci. Eng., vol. 515(1), 2019.

[4] Altinisik, A., and Hugul, O., "The Seven-Step Failure Diagnosis in Automotive Industry," Eng. Fail. Anal., vol. 116, p. 104702, 2020.

[5] Jamili and Andoko, "Stress and Deformation Simulation in 6 Hole Steel Rim Using Finite Element Method," IOP Conf. Ser. Mater. Sci. Eng., vol. 494(1), 2019.

[6] Andoko et al., "Simulation of CNC Milling 5 Axis with Finite Element Method," in AIP Conference Proceedings, p. 040013, 2020.

[7] Andoko, Paryono, Prasetya, R., Jeadi, R. P., Kurniawan, P., and Pradica, D. R., "Simulation of the Effect of Energy Absorption on Crashbox With Full Crash Initiator and Without Crash Initiator," in AIP Conference Proceedings, vol. 2262, 2020.

[8] Patil, S. and Karuppanan, S., "Modal and Fatigue Analysis of a Camshaft Using FEA,” Int. J. Appl. Eng. Res., vol. 8(14), pp. 1685-1694, 2013.

[9] Wang, G., Taylor, D., Bouquin, B., Devlukia, J., and Ciepalowicz, A., "Prediction of Fatigue Failure in A Camshaft Using the Crack Modelling Method," Eng. Fail. Anal., vol. 7(3), pp. 189-197, 2000.

[10] Suhas, K.S., and Haneef, D.M., "Contact Fatigue Analysis using Finite Element Analysis for 6 Station 2 Lobe Cam Shaft," Indian J. Appl. Res., vol. 4(7), pp. 185187, 2011.

[11] ASTM, "Standard Specification for Automotive Gray Iron Castings," vol. 03, no. Reapproved, pp. 1-5, 2000.

[12] Wang, H., Fu, C., Cui, W., Zhao, W., and Qie, S., "Numerical Simulation and Experimental Study on Stress Deformation of Braided Wire Rope," J. Strain Anal. Eng. Des., vol. 52(2), pp. 69-76, Oct. 2016. 
[13] Chen, T.-C., Chen, S.-T., Tsay, L.-W., and Shiue, R.-K., "Correlation Between Fatigue Crack Growth Behavior and Fracture Surface Roughness on Cold-Rolled Austenitic Stainless Steels in Gaseous Hydrogen," Metals (Basel)., vol. 8(4), p. 221, 2018.

[14] Norton, R. L., Machine Design: An Integrated Approach (4th Edition). 2011.

[15] Vukelic, G., and Brcic, M., "Failure Analysis of a Motor Vehicle Coil Spring," Procedia Struct. Integr., vol. 2, pp. 2944-2950, 2016.

[16] Doshi, K., Roy, T., and Parihar, Y. S., "Reliability Based Inspection Planning Using Fracture Mechanics Based Fatigue Evaluations for Ship Structural Details," Mar. Struct., vol. 54, pp. 1-22, 2017.

[17] Xin, Q., "2 - Durability and Reliability in Diesel Engine System Design,” Woodhead Publishing, pp. 113-202, 2013. 


\section{Appendix}

Table 1. Boundary condition

\begin{tabular}{|c|c|c|c|c|}
\hline Condition & Cam & Support & Force $(\mathbf{N})$ & Torsi (Nmm) \\
\hline 1 & 3 & Fixed & $1348.28(-y)$ & \\
\hline 2 & 3 & Fixed & $1348.28(\mathrm{z})$ & \\
\hline 3 & 2 & Fixed & $1348.28(-y)$ & \\
\hline 4 & 2 & Fixed & $1348.28(\mathrm{z})$ & \\
\hline 5 & 3 & Cylindrical Support & $1348.28(-y)$ & \\
\hline 6 & 3 & Cylindrical Support & $1348.28(\mathrm{z})$ & \\
\hline 7 & 2 & Cylindrical Support & $1348.28(-y)$ & \\
\hline 8 & 2 & Cylindrical Support & $1348.28(\mathrm{z})$ & \\
\hline 9 & 3 & Cylindrical Support & & 113400 \\
\hline 10 & 3 & Cylindrical Support & $1348.28(-y)$ & 113400 \\
\hline 11 & 3 & Cylindrical Support & $1348.28(\mathrm{z})$ & 113400 \\
\hline 12 & 2 & Cylindrical Support & $1348.28(-y)$ & 113400 \\
\hline 13 & 2 & Cylindrical Support & $1348.28(\mathrm{z})$ & 113400 \\
\hline 14 & 3 & Cylindrical Support + Gear Fixed & $1348.28(-y)$ & \\
\hline 15 & 3 & Cylindrical Support + Gear Fixed & $1348.28(\mathrm{z})$ & \\
\hline 16 & 2 & Cylindrical Support + Gear Fixed & $1348.28(-y)$ & \\
\hline 17 & 2 & Cylindrical Support + Gear Fixed & $1348.28(\mathrm{z})$ & \\
\hline 18 & 3 & Cylindrical Support + 1st Bearing Fixed & $1348.28(-y)$ & \\
\hline 19 & 3 & Cylindrical Support + 1st Bearing Fixed & $1348.28(\mathrm{z})$ & \\
\hline 20 & 2 & Cylindrical Support + 1st Bearing Fixed & $1348.28(-y)$ & \\
\hline 21 & 2 & Cylindrical Support + 1st Bearing Fixed & $1348.28(\mathrm{z})$ & \\
\hline 22 & 3 & Cylindrical Support + 2nd Bearing Fixed & & 113400 \\
\hline 23 & 3 & Cylindrical Support +2 nd Bearing Fixed & $1348.28(-y)$ & \\
\hline 24 & 3 & Cylindrical Support +2 nd Bearing Fixed & $1348.28(\mathrm{z})$ & \\
\hline 25 & 2 & Cylindrical Support +2 nd Bearing Fixed & $1348.28(-y)$ & \\
\hline 26 & 2 & Cylindrical Support +2 nd Bearing Fixed & $1348.28(\mathrm{z})$ & \\
\hline 27 & 3 & Cylindrical Support + 2nd Bearing Fixed & $1348.28(-y)$ & 113400 \\
\hline 28 & 3 & Cylindrical Support +2 nd Bearing Fixed & $1348.28(\mathrm{z})$ & 113400 \\
\hline 29 & 2 & Cylindrical Support + 2nd Bearing Fixed & $1348.28(-y)$ & 113400 \\
\hline 30 & 2 & Cylindrical Support +2 nd Bearing Fixed & $1348.28(\mathrm{z})$ & 113400 \\
\hline 31 & 3 & Cylindrical Support + 3rd Bearing Fixed & $1348.28(-y)$ & \\
\hline 32 & 3 & Cylindrical Support + 3rd Bearing Fixed & $1348.28(\mathrm{z})$ & \\
\hline 33 & 2 & Cylindrical Support + 3rd Bearing Fixed & $1348.28(-y)$ & \\
\hline 34 & 2 & Cylindrical Support + 3rd Bearing Fixed & $1348.28(\mathrm{z})$ & \\
\hline 35 & 3 & Cylindrical Support +4 th Bearing Fixed & $1348.28(-y)$ & \\
\hline 36 & 3 & Cylindrical Support +4 th Bearing Fixed & $1348.28(\mathrm{z})$ & \\
\hline 37 & 2 & Cylindrical Support +4 th Bearing Fixed & $1348.28(-y)$ & \\
\hline 38 & 2 & Cylindrical Support +4 th Bearing Fixed & $1348.28(\mathrm{z})$ & \\
\hline 39 & 3 & Cylindrical Support +5 th Bearing Fixed & $1348.28(-y)$ & \\
\hline 40 & 3 & Cylindrical Support +5 th Bearing Fixed & $1348.28(\mathrm{z})$ & \\
\hline
\end{tabular}




\begin{tabular}{lllll}
\hline 41 & 2 & Cylindrical Support +5 th Bearing Fixed & $1348.28(-\mathrm{y})$ & \\
\hline 42 & 2 & Cylindrical Support +5 th Bearing Fixed & $1348.28(\mathrm{z})$ & \\
\hline 43 & 3 & 2nd Bearing Fixed & & 113400 \\
\hline 44 & 3 & 2nd Bearing Fixed & $1348.28(-\mathrm{y})$ & \\
\hline 45 & 3 & 2nd Bearing Fixed & $1348.28(\mathrm{z})$ & \\
\hline 46 & 2 & 2nd Bearing Fixed & $1348.28(-\mathrm{y})$ & \\
\hline 47 & 2 & 2nd Bearing Fixed & $1348.28(\mathrm{z})$ & \\
\hline 48 & 3 & 2nd Bearing Fixed & $1348.28(-\mathrm{y})$ & 113400 \\
\hline 49 & 3 & 2nd Bearing Fixed & $1348.28(\mathrm{z})$ & 113400 \\
\hline 50 & 2 & 2nd Bearing Fixed & $1348.28(-\mathrm{y})$ & 113400 \\
\hline 51 & 2 & 2nd Bearing Fixed & $1348.28(\mathrm{z})$ & 113400 \\
\hline
\end{tabular}

